\title{
LA PROFUNDIDAD DE LA REPRESENTACIÓN: LA MIRADA FLAMENCA EN LA PINTURA Y LA LITERATURA
}

\section{Ioan Panzaru}

Universidad de Bucarest

El presente artículo propone un marco conceptual en el que podamos hablar de pintura y literatura en términos comunes, teniendo en cuenta al mismo tiempo lo específico de cada arte: Pretendemos circunscribir el tipo de complejidad que ha sido siempre imputado a los pintores flamencos y procuramos argumentar, empleando el ejemplo de Philippe de Commynes, que también (al menos algunos) escritores originarios de los Países Bajos presentan la misma característica: la mirada flamenca.

La pintura y la literatura, comprendidas (muy vagamente) como formas de representación, filtran la experiencia teniendo algunos criterios comunes. Así, un primer terreno de cooperación es la función descriptiva. Para ver en qué contexto poesis similis picturae, es suficiente recordar las descripciones medievales de algunos personajes dichos «alegóricos», como por ejemplo la Ira, la Tacañería, la Hipocresía. 
Desde este punto de vista, una pintura puede ser considerada como equivalente, al nivel de la intención simbólica, de un párrafo o de un número de versos. Aquí la correspondencia pintura-poesía se sitúa en el primer nivel, en el sentido de que (se cree que) transmiten el mismo contenido, y su contenido tiene dos niveles de significación, dado que las figuras descritas o pintadas deben ser más adelante reinterpretadas. La misma reinterpretación en el segundo nivel, es válida tanto en el caso de la obra pintada, como en el caso de la obra literaria; la interpretación en el segundo nivel no toma en cuenta el soporte o la forma de representación del primer nivel. Los emblemas de Alciato añaden en la misma página un texto a una imagen, el primero explicando a la segunda y desarrollando sus virtualidades. Desde este punto de vista, el texto y el grabado podrían ser considerados como variantes de notación de una obra ideal, que consta de un contenido puro, y que se encuentra sólo en la mente del artista. La tradición de la descripción poética de una obra plástica, ekphrasis, tan abundante por ejemplo en la Anthologia Palatina, tiene sus propios tópicos, como la extrañeza de que la figura no habla y no empieza a moverse, etc. Por fin, los retratos de Walter Scott (como los de Balzac, que siguen la técnica del escocés) son explícitamente pensados como análogos de una tela realizada por uno de los maestros que gozaban por aquel entonces de estima, como Rubens o Van Dyck.

Pero también en el plano de la tradición, entre pintura y poesía se observan diferencias importantes. El tiempo, que es la dimensión principal (o al menos la más elemental) de la narración, se deja difícilmente integrar en la imagen. La solución habitual de presentar al mismo personaje en lugares y momentos distintos para narrar un cuento es, al menos según los criterios de nuestra cultura actual, bastante difícil de aceptar. La causalidad (un fenómeno relacionado con el tiempo porque la idea de un efecto que se produce antes que la causa resulta contradictoria.), es difícil de representar en la pintura y en el dibujo, mientras que en la novela y en los textos históricos gozan de gran prestigio. La pintura puede representar las causalidades «estáticas», es decir, los efectos que se manifiestan visiblemente, como por ejemplo el pliegue de la piel de Jesús al estar sujeto por debajo del brazo, en el momento de su descendimiento de la cruz. En sentido contrario, la corporalidad de la pintura, su materialidad no pueden tener un auténtico equivalente en el arte de la palabra. La dinámica de la huella, la huella dejada por el movimiento de la mano del artista, que desempeñan un papel considerable normalmente en la pintura (mientras disminuye su dimensión simbólica) no se pueden representar en la 
literatura, aunque se pueda hablar de ello. La irradiación interna de un tejado de paja pintado por Herri met de Bles no tiene correspondencia en ninguna de las otras artes. Aquí los filósofos nos llaman la atención sobre el hecho de que en el plano fenomenal de la experiencia, más allá del contenido, existe lo que ellos llaman qualia, es decir, los aspectos irreductibles de la vivencia. El amarillo de un campo de colza florida es un quale que me impresiona y del que no puedo dar cuenta en términos poéticos. El violeta de las nubes al atardecer me produce una fuerte impresión, sin significar algo: tampoco tiene un correspondiente intencional, en el sentido clásico del término. La pintura me habla más quizá a través de qualia que a través de representaciones. En este sentido se acerca al pensamiento de aquellos filósofos del siglo XVIII que se han empeñado en bautizar su reflexión estética en un discurso sobre el sentir: aquí, la dimensión representativa de la sensación no debe ser subrayada y es completamente secundaria. De manera que, aunque a todas las artes se les puede exigir - por parte de la psicología popular - transparencia, a la pintura se le va a conceder con mucha más facilidad un alto grado de opacidad, es decir, de insolubilidad en lo representable. Es más, superar la representación se inscribe en el proyecto mismo de la estética, y Kant construye la categoría de sublime justo en base a esta idea de que el efecto de contemplación se intensifica cuando la representación se suspende. De esta manera, el arte aparece (de hecho, ya desde la antiguiedad) como un sistema que contiene su propia limitación como superación.

Sin embargo, este modo de hablar, centrado en la función descriptiva de las dos artes, tropieza con una dificultad. La función descriptiva es además explicativa, por lo tanto contiene también una dimensión interpretativa. Por supuesto, la hermenéutica no puede ser eliminada de ninguna de las ciencias del hombre, pero estaremos de acuerdo en que un uso atentamente controlado será mejor, para los fines específicamente científicos del discurso, que uno oculto o negado. Si suponemos - tal y como lo hace, por ejemplo, un exegeta de prestigio como Michel Foucault en su análisis de las Meninas de Velázquez- que los elementos de la pintura son reconocibles, identificables, traducibles a través de los signos del lenguaje (que a lo infinito y a lo vago les corresponde algo de los dos), aceptamos desde un principio que ignoramos la especificidad del trabajo del pintor, la naturaleza de los problemas que él resuelve. Actuando así, eliminamos desde un principio todas las indecisiones sobre las cuales se va a construir el trabajo hermenéutico. Se nos puede olvidar con facilidad que, para poner con el pincel los colores y, con la pluma, el recorrido de las palabras sobre el 
papel, es necesaria una actividad de construcción de la que resulte con precisión el lugar y el modo de esta colocación. Evocar un hipotético stream of consciousness lineal y monocrónico, como la cosa más evidente del mundo, no significa más que otorgar a un vacío de pensamiento el rango de principio. La construcción de la obra (construcción que, por supuesto, parcialmente precede la obra, parcialmente la acompaña, y parcialmente le sucede) puede ser considerada como un proceso que tiene lugar en un espacio multidimensional de las categorías y en un tiempo con una estructura compleja con celdas y bucles.

Me parece necesario hacer explícitamente la pregunta: ¿con qué problemas creía el pintor que iba a enfrentarse y cómo ha pensado resolverlos? Luego voy a hacer la misma pregunta al intérprete, y tratándose de mí mismo como intérprete, me exigiré precisar qué indecisiones he eliminado para construir la interpretación.

Paralelamente, haré la misma pregunta en relación con el trabajo del escritor: ¿cuáles son sus problemas, en qué medida se pueden adivinar éstos juzgando en función de la superficie de la obra (si no incluso las palabras y los sentidos idiomáticos) que trabajan durante la construcción de la obra?

Michael Baxandall tuvo la idea de investigar qué categorías se utilizaban durante el Renacimiento para caracterizar la pintura de los maestros. Descubrió que a las obras de Botticelli, por ejemplo, se les atribuía una aria virile, que hoy no nos resulta fácil identificar. Reconocer nuestras categorías actuales, es más, el progreso de las categorías del pensamiento actual (en términos de resolución y refinamiento de discriminación), en todas las obras del pasado, significa reintroducir por la puerta de atrás un etnocentrismo que hemos echado con mucho jaleo por la puerta principal. Una renovada tentativa de arqueología del pensamiento, que intenta reconstituir modalidades pasadas de concebir e interpretar las obras de arte, sin recurrir a la empatía o a la intropatía, y sin renunciar al ideal de tratar de producir nuevas categorías para conferir al entendimiento un nuevo estado, se sitúa necesariamente cerca de la manera de pensar de las ciencias cognitivas.

El lenguaje teórico común, capaz de describir en la misma medida las obras de la pintura y de la literatura, podría ser construido partiendo del concepto de representación. La representación es un concepto que se encuentra con predilección en el campo de la filosofía y de la psicología. En el primero, designa la idea que un espíritu se hace sobre 
los estados de las cosas del «mundo». Tratándose de una referencia a un estado de cosas, puede ser descrita como formada por oraciones lógicas. Por supuesto, todo el encanto del discurso filosófico sobre las representaciones de otros consiste en demostrar que éstas son falsas.

En la psicología, la representación es la función de la mente por la que se evoca un conocimiento en relación con objetos ausentes o que no han sido todavía objeto de la experiencia. Es una función que la evolución de la vida inserta entre percepción y pensamiento reflexivo, estrechamente relacionada con la memoria. La representación, teorizada por Serge Moscovici, designa en la literatura de los últimos cincuenta años una forma de sistematización de unos conocimientos, que se transmite por medio de mecanismos sociales y tiene el papel de informar a la experiencia. El término de representación ha llegado, en disciplinas conexas como por ejemplo la sociología, a designar distintos tipos de prejuicios, de biases, como dicen los americanos. El valor positivo de la representación reside, sin embargo, en que permite la comunicación social mediante referencias cortas a paquetes de ideas complejos.

La ruptura con la tradición clásica aparece cuando distinguimos firmemente entre ektypia, transposición de unas propiedades del objeto por la intervención de unos procesos físicos causales (la sombra, la huella, la fotografía, la imagen electrónica), y representación, actividad del espíritu. De este modo el arte aparece como la puesta de los procesos ectípicos al servicio de la representación, que los domina discretamente.

Por representación artística entendemos la relación compleja y estructurada entre la intención de figuración y los elementos de la obra. Aquí el proceso es inverso al de la psicología: en lugar de llegar a una configuración intencional, partiendo de una experiencia u otra fuente de información sobre el mundo que nos rodea, se parte de ésta para construir, con los medios facilitados por la práctica de la sociedad, un objeto que mueve estos contenidos y que favorece experiencias consideradas socialmente válidas, incluso preciosas. El arte es representación de la representación, es decir, una comunicación de unas experiencias y contenidos por medio de unas técnicas y materiales socialmente aceptados. Desde este punto de vista, es significativo si el arte llamado escultura, por ejemplo, reconoce una sola materia significante, el mármol, o si una lata de Coca Cola aplastada puede aparecer en una obra. $\mathrm{Si}$, en el deseo de ilustrar las posiciones relativas de las tropas combatientes en Waterloo, utilizamos el plato para 
figurar el cuartel general de Wellington, el tenedor para las tropas de Ney y el salero para la finca La Haye Sainte, vamos a desvelar una función de figuración: los objetos mencionados se vinculan a las posiciones de los ejércitos por una relación de referencia arbitrariamente constituida. Generalizando esta relación, podemos decir que hay una fungibilidad general, en el sentido de que todos los materiales constituyen un soporte potencial para la comunicación en el sentido amplio que ofrece el arte. Los mejicanos pintan el icono de la Virgen María con plumas de papagayo, mientras que los polinesios hacen mapas de nácar y fibras de palmera.

Para que la fungibilidad potencial de un objeto se actualice, es necesario que él sea reconocido como remitiendo a algo. Más exactamente, parcialmente o en totalidad, debe ser integrado en una lectura que descubre una intención figurativa. Las constelaciones pueden ser consideradas como un ejemplo típico de actualización de lo fungible: donde algunas poblaciones ven una osa, otras descubren un carro. Lo icónico no oculta por completo lo fungible: así, las fotografías (que según la tradición antropológica hubieran podido ser en cierto momento objetos sin significado para otras poblaciones aisladas) necesitan a veces explicaciones incluso para el ojo experimentado. Un ejemplo todavía más claro es el de un diagrama, del que no resulta claro si se trata de la evolución de las personas mordidas por los perros en Bucarest o de la variación de la densidad de los crustáceos de las aguas de la Antártida. Según la definición de Peirce, el diagrama constituye la esencia de la iconicidad; sólo que la relación de referencia no es intrínseca a lo icónico, o mejor dicho, aquella forma que le es intrínseca, es plurívoca y confusa. Resulta que no podemos decidir a priori si un objeto representa o no; precisamente para eliminar esta indecisión, las sociedades utilizan sustancias reservadas para las representaciones: el mármol, los pigmentos en aceite de lino, el papel.

Aquí apelamos a la noción de sistema de representación, que cubre la arquitectura semántica que se encuentra detrás de la producción del objeto. Se dice del pintor alemán Caspar David Friedrich que, recibiendo una vez la visita del francés David d' Angers, se quedó descontento porque éste no logró comprender, mirando un cuadro en el que un cisne nadaba por entre las cañas, que el tema de la imagen era la idea de deificación. El sistema de representación de Friedrich tenía también dos niveles de lectura, es decir, poseía (para emplear las nociones introducidas por Erwin Panofsky) también una iconografía y una iconología. A diferencia de la alegoría medieval, él suponía una 
intropatía eurística. La construcción del sistema de representación es una decisión estratégica esencial (que la historia toma por nosotros) que determina la forma de los significados que se van a emplear. Se sabe que el arte del realismo socialista presentaba imágenes de la maternidad que eran análogas a las imágenes de la Virgen María. La maternidad como valor socialista simboliza una tautología del pueblo que se autoconfigura y se regenera. Doce siglos antes, los Libri Karolini, escritos por orden de Carlomagno, se preguntaban cómo se puede establecer si una mujer con un niño entre los brazos representa a María con Jesús, o a Andrómaca y Astyanax. Un mismo objeto, por ejemplo «los ídolos de Troya», tan frecuentes entre los restos desenterrados de las comunidades neolíticas, habrían podido tener significaciones distintas en las diferentes culturas, esparcidas en un área tan extensa en el Oriente Cercano y en el sur este de Europa. Lo mismo pasa con el signo llamado svastika que es sagrado para los indios y odioso para los europeos, por medio de la metáfora en los primeros y por la metonimia en los segundos.

La semiología de la imagen implícita en lo arriba mencionado, supone que la lectura de una imagen tiene lugar partiendo de una serie de «elementos minimales», organizados a un nivel que debe ser llamado «umbral de representación». Los elementos minimales no son las sombras de color o las palabras, sino las áreas de identificación. Por ejemplo, en la nieve es blanca, el area reconocible como representación es toda la oración. (Es importante distinguir entre signo y representación, ejercicio semiótico impuesto del que me voy a dispensar aquí para no permanecer en la zona propedéutica.) En él camina triste, hay dos oraciones de profundidad: él camina y él está triste, es decir, dos áreas de identificación. René Huyghe (1965) ha publicado en Puissances de l'mage ${ }^{1}$, la foto de la nariz de un personaje pintado por Rembrandt. Siendo más pequeña que el área de identificación, la fotografía nos presenta sólo una mancha blanca, en la que ni siquiera con la mayor benevolencia se puede reconocer la iconicidad, es decir, el parecerse a una nariz. A pesar de todo eso, el relieve de la pasta muestra que la zona ha sido fuertemente trabajada por el pincel del artista y ha pasado por varias fases de elaboración, guardando las huellas de unos rasgos con trayectos distintos. Si son suficientemente «grandes» para ser reconocidos, tales elementos de representación se

1 Macrofotografía, a plena luz, de un detalle del Hombre con el bastón, cuadro del Museo Louvre (Huyghe, 1965: 53). 
pueden ver como analogías de las oraciones que tienen un predicado de existencia, como por ejemplo una nariz es. Lo mismo pasa en la poesía, las palabras, inseparablemente ligadas por su función semiótica, pueden evitar llegar, sin embargo, a una función de representación.

En la zona del umbral de la representación, la manera de identificación de estos elementos determina la interpretación del mensaje. Se conoce la célebre frase latina: mea pater, mea mater, filium tuum lupus est, donde mea no es el posesivo femenino, sino el imperativo del verbo meare, «ir» y est no es el presente del verbo esse, sino del verbo edere, «comer». Esta interpretación se valida por el hecho de que mea pater no es una expresión gramatical, pater siendo masculino, y que el acusativo filium tuum no se puede justificar en la versión que identifica los términos con sus homófonos más corrientes. De la misma manera, Hamlet puede ser el drama del hijo que venga a su padre (en el primer nivel de la ambivalencia de los sentimientos que nutre hacia él), o puede ser, en la misma medida, la tragedia de un espíritu contemplativo que no se siente entrenado en la carrera para los bienes de este mundo. Aquí podemos pensar en un test de validación análogo al test de gramaticalidad, pero tenemos que reconocer que la obra está construida de tal manera que permite la validación de varias interpretaciones.

Un análisis del problema de la interpretación (Pânzaru, 2000) nos ha llevado a la conclusión de que la interpretación es posible por la asociación de unos elementos del interpretandum con categorías corrientes en la cultura del exegeta. La identidad de una cultura en esta perspectiva está dada por la identidad de un conjunto de categorías con una estructura dada. Tanto la arquitectura del conjunto, como el contenido de las categorías, cambian con el tiempo. De tal modo que algunas culturas pueden ser presentadas (partiendo de la bien conocida teoría de las catástrofes de René Thom) como unas hojas (no planas) con pliegues. En el lugar donde se produce el pliegue, la hoja pasa tres veces por la misma vertical. La misma palabra o elemento de representación cobra sucesivamente tres valores. Por ejemplo, la idea de profeta en el Antiguo Testamento está ligada en la historia de Moisés, a una relación personal directa entre el profeta y la divinidad, al igual que a una función histórica actualizada del profeta, líder y salvador del pueblo, que por su mediación, es pueblo de Dios. El profeta del Éxodo es por lo tanto la forma eficiente por la que Dios desciende la mano sobre su pueblo: El Señor golpea la roca para sacar agua, separa las olas del Mar Rojo, y cura por la serpiente de cobre. Después del período de los 
Jueces, el mismo concepto de profeta aparece de manera distinta: Samuel unge a Saúl y a David, y luego se ve obligado a huir para salvarse de la ira del primero. La relación de comunicación entre el profeta y la divinidad se mantiene, enfocada en la elección de Israel (que se va a manifestar por David), pero no aquella forma de la transmisión de poder («la mano» de Dios). Por fin, los profetas menores asisten pura y simplemente, bastante asustados, a las equivocaciones de su pueblo, sin poder hacer otra cosa que demostraciones espectaculares como Ezequiel. En este período de ocultación de la elección, Osea concibe, sin embargo, la idea de amor que sería característica del hombre justo y a fortiori del profeta. En el Nuevo Testamento, Jesús aparecerá tanto como una intensificación de Moisés (a través de quien el poder soteriológico se ejerce eficazmente y para siempre), como una intensificación del poder del amor del justo e impotente ante la maldad de este mundo. Se ve, por lo tanto, que el Antiguo Testamento completa un pliegue integral, lo que le confiere obviamente estabilidad de categoría.

Si se acepta este análisis, la interpretación aparece en simetría con la representación artística, es decir, tiene que ver con la reconstrucción del sistema de categorías incorporado en la obra. Aquí, por supuesto, la representación comprendida como «figurativa» ya no es pertinente, debido a que las categorías pueden ser «no figurativas», y lo que importa es la traslación (difícil o defectuosa) de los sistemas de categorías por inducción, intuición, etc.

Por otra parte, el estudio de la representación artística es una de las caras de una hoja, la otra es la hermenéutica. La teoría de la representación y la hermenéutica funcionan como límite la una de la otra, es decir, prestándose más o menos explícitamente las ideas la una a la otra, se impiden mutuamente superarse y se mantienen en una perfecta conmensurabilidad. Por otra parte, el sistema de categorías resultado de su trabajo común no puede ser puesto bajo el signo de la conformidad, porque va a integrar muchas incertidumbres, al mismo tiempo que ofrece respuestas netas a una serie de indecisiones. ¿En qué medida el sistema de categorías del intérprete constituye un mapa fiable para el otro? ¿En base a qué criterios podemos verificar el dibujo del mapa?

La teoría de las categorías de las matemáticas nos puede sugerir en este punto ideas interesantes. En esta teoría, que se dedica completamente al estudio de unas propiedades de los conjuntos de relaciones, se utiliza la noción de structure preserving map, mapa que mantiene la estructura. Una categoría está compuesta por un conjunto de relacio- 
nes entre grupos de elementos, de tal manera que un grupo es la imagen de otro, es decir, lo dibuja guardando su estructura. La relación entre dos elementos, dentro de una categoría, se llama morfismo: $f: a \rightarrow b$. Los morfismos son asociativos, se pueden componer y mantienen su identidad. Los morfismos entre categorías son dados por las funciones y son el dibujo de un mapa de una categoría encima de la otra, manteniendo la estructura.

El análogo del morfismo en el estudio del arte sería la idea de relación de representación de una categoría (esta vez, en sentido amplío, de noción o concepto) por medio de un procedimiento incorporado en la obra. Abordar la iconología (que llama la atención, por ejemplo, sobre el hecho de que lo divino está representado a través de la asociación de una figura humana con un aura redonda, y el papel social notable de alguien puede ser indicado por un aura cuadrada ${ }^{2}$ ), constituye obviamente un punto de partida en esta dirección. De este modo se adelanta en una cuestión importante, es decir, al aclarar cuáles son las convenciones de representación de una cultura, se indica lo que no es problemático para el artista. Uno de los primeros descubrimientos que vamos a hacer por esta vía es que las relaciones de representación son heterogéneas: por ejemplo, en el caso de un mapa tenemos una relación analógica cuando esbozamos el contorno de un río, y una relación simbólica cuando la ubicación de una iglesia se indica a través de una cruz. El uso del color en geografía es un ejemplo de cómo se sobrepone el mapa de un conjunto (los tonos de color) sobre otro (la escala de las alturas del relieve). ¿Podemos quizá concluir que una obra de arte aparece desde este punto de vista como un conjunto no estructurado por las categorías (en el sentido matemático), es decir, por pares de conjuntos homologados de manera convencional, pero no (obligatoriamente) integrados por las funciones en una estructura única y consolidada?

El marco en el cual se desarrolla el trabajo de la representación artística, es decir, el de la actualización de unas fungibilidades para transmitir contenidos y facilitar experiencias de valor, constituye un espacio de inteligibilidad. Esta oración no se refiere en ningún caso al funcionamiento del arte en la sociedad, sino solamente al contexto arriba definido, en el que la interpretación incumbe la fabricación de unas recons-

2 (Wirth, 1989: 99, ill. 8). Se trata de un mosaico que data de aprox. del año 630, de la iglesia de San Demetrio de Salónica, que representa al prefecto Leontios y al obispo Juan de un lado y otro del santo patrón del templo. 
trucciones hipotéticas del sistema de categorías que ha informado la interacción entre el creador y la obra. Por otra parte, destacamos que en este marco, el creador y el investigador de la obra se definen solamente como nomotetas que instituyen relaciones entre un sistema de categorías y un objeto, y por consiguiente son indiscernibles.

¿Hay un espacio de inteligibilidad tanto en la pintura como en la literatura? ¿Cómo se puede mostrar, poner de manifiesto?

Por supuesto, las diferencias son las que se le imponen primero a la observación. La narración está centrada de costumbre en una idea de causalidad, limitada por la idea de sucesión. La sucesión domina, aunque esté fragmentada y sus segmentos mezclados, pero la inteligibilidad se da por medio de las ventanas de causalidad que se abren aquí.

En segundo lugar, la palabra inteligibilidad, con su aura universal, oculta el hecho de que hay varios modelos de inteligibilidad concurrentes. Por ejemplo, la racionalidad teleológica está relacionada con el cálculo de las oportunidades en función de un fin, la intelectualidad se define por la capacidad de abstraer conceptos y posiblemente de contemplarlos, la heurística representa la posibilidad de descubrir conocimientos nuevos. El modulo estándar del espacio de inteligibilidad se define desde la antigüedad por una forma de representación que es el problema.

El problema se compone de un enunciado, seguido de una pregunta (la parte visible), de un grupo de conceptos, relacionados entre sí por relaciones (la parte teórica), de un método de resolución y un método de validación (la parte pragmática).

¿Acaso podemos decir, y en qué sentido, que un artista resuelve un problema? En el altar Portinari, pintado por Hugo van der Goes (y es por aquí por donde llegamos a la cuestión de la «mirada flamenca»), el retablo central está ocupado por una Adoración de los pastores. Como se sabe, en la iconografía de este tema se acostumbra marcar los dos tiempos sucesivos: uno, en el que los ángeles avisan a los pastores, y otro, en el que estos últimos vienen a saludar al niño Jesús. La representación, en el mismo espacio, de dos hechos sucesivos no constituye para el pintor un problema, ya que está resuelto tradicionalmente por la ubicación de la escena anterior, y secundaria, en un espacio marginal del tema central. El problema, para Hugo van der Goes, lo constituye la relación entre los dos momentos. Un factor de relación es la identidad de los personajes. Pero para que ellos sean reconocibles deben ser suficientemente grandes, vestidos igual, con rasgos anató- 
micos identificables. De este modo lo hace Dieric Bouts en La Justicia de Otto el tercero, por ejemplo. En el retablo central del altar Portinari, sin embargo, no queda lugar, dado que el pintor tiene ya decidido presentar aquí un montón de ángeles y tres pastores. Por lo tanto, les dota a estos últimos de un utensilio grande, de palo largo, una especie de pala para desenterrar raíces (¿comestibles?). Los personajes pequeños y lejanos se van a identificar, por lo tanto, fácilmente, según este utensilio bastante llamativo. El instrumento tendrá una función semántica, una vez reconocido como área de identificación, en dos niveles: figuración de un utensilio que etnográficamente indica el grupo de los pastores, pero también auxiliar para figurar la relación de sucesión entre dos escenas. Tenemos, por lo tanto, los conceptos sucesión, identidad, elemento de reconocimiento, junto con las relaciones evidentes entre ellos ${ }^{3}$. El método de resolución de van der Goes es heurístico (le ha venido esta idea, teóricamente equivalente a otras) y el método de validación es la consolidación de las correspondencias entre el grupo en adoración y los que reciben la noticia. En realidad, uno de los pastores, el más joven, una especie de simple d'esprit, parece llegar a toda prisa, a punto de tropezar con los otros. En su rostro se lee una especie de sorpresa, pero también la espera de un acontecimiento importante y difícil de entender. Otro pastor, el más viejo, se ha apoyado en una rodilla, en una actitud que es la réplica a la que adopta su correspondiente en la colina delante del ángel que indica con la mano hacia la escena principal. La atención que el pintor presta a la psicología por medio de estas figuras de hombres sencillos es el indicio de que éstas sirven a la resolución de otros problemas, que, sin embargo, no vamos a discutir aquí.

Otro problema, menos evidente, está relacionado con la manera de ubicar la escena alejada en el paisaje y la manera de referirse a ella. Van der Goes ha elegido no evidenciarla en la indeterminación, situándola en una zona abierta hacia el horizonte, sino encuadrarla como en un marco. Por supuesto, la iconografía de la época, es decir, el sistema

3 Se puede argumentar que van der Goes ha sacrificado aquí la identidad de los personajes de las dos escenas, proponiendo un revestir continuo, es decir, dos escenas simultáneas, una con un grupo de pastores a los que se les ha dado la noticia y otros que la reciben en este momento. Pero esta línea argumentativa no cambiaría demasiado el razonamiento de este artículo. La identidad de los personajes de las dos escenas es indecible, ya que las figuras alejadas son demasiado pequeñas; la identidad de su papel está asegurada por el uso del instrumento para cavar; la continuidad entre los dos grupos está validada por el movimiento del joven de pie, y por los otros dos personajes que le siguen. 
de las reglas corrientes en aquella cultura de la imagen, nos dice que dos escenas sucesivas pueden ser situadas en rectángulos adyacentes (cuadros sucesivos), o pueden (como en La Justicia de Otto) ser integradas en un paisaje único y articulado, como si se implicaran personas distintas en lugares próximos y en el mismo momento del tiempo. Los marcos dan igual importancia (o proporcional con el área del marco y su posición) a cada escena, mientras que la ubicación en tópicos del mismo paisaje los jerarquiza según la cercanía y la centralidad. El problema del pintor es, por lo tanto, dar un máximo de importancia a la escena del anuncio, integrándola al mismo tiempo lo mejor posible en la escena de la adoración. La solución es de nuevo heurística. Existe en la iconografía de la Adoración un elemento productor de marcos, el armazón del cobertizo donde se encuentra la comida de los animales. La idea de van der Goes es encuadrar el Anuncio en un rectángulo formado por la madera del techo con las columnas de apoyo. Como extremo refinamiento, el pintor nos presenta las huellas de los golpes de hacha que han dado a la contraficha un cabo punzante que corresponda con el ángulo, poniendo de manifiesto el contraste entre la cáscara del palo de haya y la luminosidad del interior cortado.

Con esto hemos tocado el punto sensible del problema de «la mirada flamenca». ¿Por qué era necesaria tanta meticulosidad, para que figuraran no sólo la estructura del tejado, sino también las huellas de los utensilios con los cuales sus elementos han sido trabajados? ¿Por qué hacía falta tanta racionalidad, y tanta complejidad en la racionalidad?

Ya desde el siglo XV, cuando el Maestro de Flémalle y luego los hermanos van Eyck han dado una fórmula propia a la perspectiva de profundidad y luego han explotado el potencial de los óleos de manera genial, los observadores italianos y españoles han notado esta característica, que han atribuido inmediatamente a un factor étnico: el ojo flamenco. Cientos de años más tarde, Hippolyte Taine (Philosophie de $l^{\prime}$ art, la traducción rumana de 1974: 144-174) aún intentaba una explicación en la misma dirección, acentuando la orientación determinista, sin embargo dándole una forma compleja y matizada. El flamenco, dice Taine, tiene un physique épais, le faltan, la gracia y la volatilidad del italiano. Como todos los germánicos, es poco sensible ante los placeres sensuales y, por lo tanto, es más difícil de distraer, por lo que tiene una capacidad de trabajo muy especial. Su imaginación trabaja en régimen concentrado, no se desvía a menudo hacia canciones, conversaciones, por lo tanto, la actividad germánica proporciona productos compactos, que destacan por el pensamiento incorporado. Podríamos 
deducir de ello que van der Goes se ensimismaba tanto en su trabajo, que no paraba de introducir detalles, teniendo éstos un papel compulsivo, casi neurótico. El lector de Taine no puede contenerse a la hora de sospechar aquí un prejuicio italiano, es decir, un bias a favor del modo italiano, conceptual y simplificador, de tratar la representación artística.

Las explicaciones deterministas provocan en realidad mi desconfianza. No es menos verdad que, en el siglo XX, los trabajos de Magritte o de Delvaux recuerdan la minuciosidad de sus antepasados. Delvaux, pintando una estación, indica cada trozo del vagón, cada aislante de los palos de telégrafos. Es cierto que «el ojo flamenco» nos plantea a su vez un problema. Podríamos intentar evacuar la dificultad hablando de mentalidades específicas de una época, tal y como lo hace (con fundamento, en el campo de su propio discurso) Erwin Panofsky en Early Netherlandish Painting, y concluyendo que un místico como van der Goes dedicaba su actividad a Dios, trabajaba para Dios, acumulando los detalles y multiplicando el trabajo para homenajear mejor a Dios. Pero Delvaux es un pintor anticristiano, que ha presentado en bastantes trabajos esqueletos crucificados, para que no puedan acusarle de devoción religiosa.

El problema del ojo flamenco se amplifica si lo buscamos, además de en pintura, en la literatura. Es verdad que, en comparación con el volumen inmenso de pintura flamenca, la literatura correspondiente es mucho más rara, por lo que un exegeta pudo decir que en el momento de la publicación de Ulenspiegel, de De Coster (1867), la literatura belga no había registrado ninguna obra más desde Froissart, desde finales del siglo XIV. (Hay aquí un poco de maldad, porque el último literato belga medieval es Philippe de Commynes, que empieza a escribir sus Memorias hacia 1489.) Pero, en De Coster encontramos seguramente un análogo de esta profundidad de justificación de la representación, bajo la forma de una colección de detalles cuya función queda por determinar. Tomemos, al azar, el pasaje en el que el futuro Felipe II de España, por el momento sólo un bebé, recibe regalos, con motivo de su bautizo:

Madame de la Coena lui appendit au cou une pierre noire contre le poison, ayant forme et grosseur d'une noisette, dont l'écale était d'or. Madame de Chauffade lui attacha à un fil de soie pendant sur l'estomac une aveline précipitative de bonne concoction d'aliments; messire van der Steen de Flandre lui offrit un saucisson de Gand, long de cinq coudées et gros d'une demie, en souhaitant humblement à Son Altesse qu'à sa seule odeur elle ê̂t soif de clauwert gantoisement, disant que quiconque aime la bière d'une 
ville n'en peut haïr les brasseurs; messire écuyer Jacques-Cristophe de Castille pria monseigneur Infant de porter à ses pieds mignons jaspe vert pour le faire bien courir.

De Coster nos ofrece un poquito del enciclopedismo del siglo XVI, heredero de los lapidarios medievales, integrado en una escena en la que el número de los detalles es más que suficiente para el efecto real, incluso es demasiado abundante. Es inútil decir que los nombres de los personajes del párrafo anterior no se volverán a encontrar nunca en la novela. ¿Acaso era necesario que se nos dijeran las dimensiones del chorizo de Gand, o que se nos indicara el nombre flamenco de una especie de cerveza, el clauwert? Recuerdo la observación de Eugene Vance que decía que en la obra de San Agustín no existe casi ningún elemento visual, que pueda ser imaginado.

Commynes es seguramente flamenco, porque su padre se llamaba Colard van der Clyte y había sido bailli de la ciudad de Gand. Su madre era Marguerite d'Armuyden. Se debe precisar, para los menos familiarizados con la historia de la cultura de los Países Bajos, que los flamencos de Flandes (término medieval que no se debe confundir con el significado actual acordado al etnónimo «flamenco») eran francófonos, al menos, la clase culta. De Coster (nombre que significa en neerlandés «sacristán») era por supuesto también francófono, 450 años más tarde. Hemos elegido para la discusión un pasaje del comienzo de las Memorias de Commynes, en el que cuenta la batalla de Montlhéry, de 1465.

El memorialista tenía por aquel entonces 18 años y acababa de entrar al servicio del conde Charolais, el futuro Carlos el Valiente de Borgoña. Carlos no era demasiado viejo (había nacido en 1433), pero una auténtica madurez nunca iba a alcanzar. Estamos, por lo tanto, ante un testimonio anclado en una de las experiencias de juventud. No es muy reciente, ya que el autor la dicta a la edad de 42 años, lo que significa que había sido probablemente contada de nuevo y rememorada varias veces en la mente de Commynes, pero una serie de características siguen guardando su frescor.

Tenemos, en el texto, una imagen extremadamente clara y precisa de las situaciones, de las posiciones relativas y de los acontecimientos observables. El rey Luis XI vuelve desde el este, y el conde de Charolais le ataca viniendo desde el norte hasta el sur de París, en una tentativa simultánea de juntarse con las tropas de los duques de Bretaña y de Normandía, que sin embargo tienen retraso. Carlos había 
establecido que la batalla se diera cerca de Longjumeau, donde había podido instalar un fuerte campamento en la cuesta de una colina, y había reservado para la vanguardia, dirigida por el conde de SaintPol, el papel de establecer el contacto con el enemigo en Montlhéry, un pueblecito del valle, y de retirarse luego en el campamento. Pero la víspera del día respectivo, viendo venir uno a uno y tomar posición delante de la aldea a los arqueros del rey, el conde de Saint-Pol se da cuenta de que no va a poder dominar a sus tropas si da la orden de retirada, cualquier maniobra de distanciamiento amenazando con transformarse en confusión y con traer la masacre. Por consiguiente, le manda por la noche un mensajero a Carlos con la misión de presionarlo con ruegos insistentes para determinar que la mayor parte del ejército llegase detrás de él a Montlhéry. El conde de Charolais acepta esta petición, por lo menos extraña, y llega por la mañana hacia las siete delante de las posiciones enemigas. El joven Commynes está a su lado. Los dos ejércitos están separados por un seto muy denso y largo. En lugar de cambiar sus posiciones, se van a separar cada uno en dos y van a atacar por los dos extremos del seto. En el flanco izquierdo, donde se encuentra el conde de Saint-Pol, los borgoñeses son vencidos y echan a correr, perseguidos por los enemigos. En el flanco derecho, donde manda Carlos, los borgoñeses rompen la línea de los enemigos y se lanzan a perseguirles. El avanzar es difícil porque, dice Commynes, estoient les champs pleins de bleds et de fèves, et d'autres grains très forts, car le territoire y estoit bon ${ }^{4}$. Pero el conde de Charolais se lanza a perseguirles con tanto ánimo, que pronto constata que se ha quedado solo con unos cuantos hombres. Aconsejado por un gentilhombre de más edad, que había luchado también durante las guerras con los ingleses, el joven se detiene e intenta retirarse hacia las propias líneas (que habían sido esparcidas). Pasa al lado del castillo de Montlhéry (fortaleza del rey ${ }^{5}$ ), de donde sin embargo, los arqueros de guardia sólo lo miran sin hacer nada. Alejándose, es atacado por una tropa de unos dieciséis enemigos; como la baviera, es decir, una pieza de armadura que le cubría la boca, la barba y la parte superior del pecho, no había sido bien atada por la mañana, se había desprendido durante el galope y se le había caído, el joven recibe un golpe de espada en el cuello que le llena de sangre. Commynes menciona que había visto caer la baviera, et luy avoye vu choir, pero no había podido intervenir. Los hombres del rey

4 Commynes, en Pauphilet (ed.) (1952: 964).

5 Es probable que el rey Luis XI estuviera en la torre del castillo y mirara. 
apresan a Carlos para llevárselo como rehén (evitan matarle para no perder la recompensa). Afortunadamente, en la tropa del futuro duque, hay un muchacho fortachón, hijo de un médico, por lo tanto no noble, pero que en esta circunstancia se muestra a la altura. Estando a caballo, un caballo voluminoso, se echa con fuerza en medio del grupo y logra separarles. Sin más remedio, los hombres del Valiente se retiran. Miran a su alrededor esperando ayuda de los que estaban por ahí, y realmente llegan grupos, pero muy poco numerosos. No tienen ni cien hombres. Les bleds estoient grands, et la poudre la plus terrible du monde; tout le champ semé de morts et de chevaux; et ne se connoissoit nul homme mort, pour la poudre. A lo lejos aparece una tropa con la bandera del conde de Saint-Pol, que ha vuelto a buscar a su amo. Pero no llegan a cuarenta. A Carlos le parece que avanzan muy lentamente; tres o cuatro veces les envía decir que se dieran prisa, como si no entendiera el apremio con el que se le esperaba, el conde de Saint-Pol ordena a sus hombres recoger, por el camino, las lanchas esparcidas por el suelo ${ }^{6}$.

Esta historia densa e importante se sitúa en un espacio de inteligibilidad fácil de explorar. Es verdad que la lectura del texto original es difícil. Commynes dicta a un escribano. Su frase es desordenada y desequilibrada, las referencias confusas. Todos los personajes tienen nombres franceses, de tal modo que hay que hacer un cuadro para entender quién en qué tropa está. Pero una vez superados los aspectos de legibilidad, constatamos que el autor nos transmite - a nivel liminal e implícito, específico de la lectura interpretativa - todos los elementos necesarios para permitirnos reconstruir un significado bien estructurado, rico en detalles, consolidado por una racionalidad general, pero al mismo tiempo sembrado de aspectos imprevisibles, inverosímiles, con accidentes increíbles. Leyendo la pintura flamenca ahora desde la literatura, ¿no son éstos los ingredientes de las obras de ambas artes? Es más, ¿no es el espacio el héroe principal del proceso de la representación, tanto en el retablo central del altar Portinari, como en la narración de esta batalla, en la que las tropas borgoñesas se separan en dos y tiran en sentido contrario, para que luego intenten reunirse, con dificultad, avanzando penosamente por el trigo alto, y acercándose lentamente, demasiado lentamente, como en una pesadilla en la que la distancia tamiza la arena del terror como por una clepsidra?

6 Puede verse el análisis de la batalla de Montlhéry en Kendall (1974), siendo interesante el sitio web de la ciudad: http: // montlhery.com. Se podrá ver que las informaciones históricas no difieren en mucho de las recogidas por Commynes. 
El problema de la construcción del espacio en la pintura, resuelto de manera magistral, según es sabido, aunque imperfectamente, a principios del siglo $\mathrm{XV}$ por el aparato formal de la perspectiva, puede ser comprendido como un caso particular de la construcción de un espacio de inteligibilidad, que permite el acercamiento, la adquisición de la experiencia, y su dominio. El descubrimiento de la perspectiva no es más que el comienzo. La fuerte estructuración del texto de Commynes, que hace que toda la batalla de Montlhéry derive de una palabra dicha por Carlos, un día que había sido humillado por su padre en presencia del embajador del rey, y que compara siempre las intenciones con las realizaciones, redactando al final de cada capítulo una especie de informe destinado a llamarnos la atención no sobre las reglas, sino los tipos de acontecimientos frecuentes en el mundo de los príncipes, esta estructuración puede ser leída como el signo de una necesidad, una necesidad de racionalidad, una necesidad de complejidad. La complejidad deseada por Commynes - y al mismo tiempo por los flamencos que hemos mencionado aquí- es de tipo especial.

A diferencia de los italianos, que en el arte muestran una propensión hacia el descubrimiento de los principios y de las estructuras, dejando de lado los detalles, los flamencos se basan en las primeras, pero integran también a los últimos, dejándoles incluso proliferar. Los italianos prefieren poner de manifiesto el marco general de inteligibilidad, la estructura del espacio, las proporciones, las regularidades. Los flamencos añaden a este marco general un proceso de regionalización, de localización, que produce nudos, a su vez generadores de particularidad, de aberración, de contingente. Los italianos aciertan, los flamencos problematizan. Los italianos regularizan, los flamencos particularizan. Al igual que la lógica de lo individual de Scot, que no suprime las universalias, pero las crea en base al poder de localización de la existencia, la pintura flamenca textualiza el espacio. Esta textualización, esta construcción celular del contenido intencional, son especialmente importantes en la prosa de Philippe de Commynes.

La respuesta que propongo aquí a la cuestión de la mirada flamenca no está ligada a una tipología étnica. Propone sobre todo un comienzo de tipología cognitiva. Los que, sea cual sea el país en el que hayan nacido, no se conforman con comprender los hechos aislados, sintiendo la necesidad de llegar a las generalizaciones, pero que se descubren insatisfechos por la simple enunciación de los principios, buscando más adelante, dominados por una especie de hambre análoga a aquel desiderium naturale del que hablaba la escolástica, de cerrar el círcu- 
lo, y bajar del tipo al individuo, de lo espacial a lo topológico, de la probabilidad al accidente, de la coherencia a la incongruencia, los que desean representarse al mismo tiempo el marco de inteligibilidad general y las regiones particulares de inteligibilidad que son los problemas, la causa y la consecuencia, la regla y la excepción, son aquéllos que poseen la mirada flamenca.

\section{Referencias bibliográficas}

BaXANDAll, M. (1985). L'Oeil du Quattrocento. L'usage de la peinture dans l'Italie de la Renaissance. Paris: Gallimard.

COMMYNEs, Ph. de (1972). The Reign of Louis XI 1461-1483. Translated with an Introduction by Michael Jones. London: Penguin Books.

HuYGHe, R. (1965). Les puissances de l'image. Paris: Flammarion.

Kendall, P. M. (1974). Louis XI. Paris: Fayard, Le Livre de poche.

MARQuis, J. P. Category Theory, Stanford Encyclopaedia of Philosophy, http://plato.stanford.edu/entries/category-theory.

PANOFSKY, E. (1958). Early Netherlandish Painting. Its Origins and Character. 2 vols. Cambridge, Massachusetts: Harvard University Press, t. I.

Panzaru, I. (2000). Tehnici ale interpretării de text. Iasii: Polirom.

PAUPHILET, A. (ed.) (1952). Historiens et chroniqueurs du Moyen Age, édition établie et annotée par Albert Pauphilet, textes nouveaux commentés par Edmond Pognon. Paris: Bibliothèque de la Pléiade, NRF, Gallimard.

TAINE, H. ([1924] 1974). Filozofia artei. București: Editura științifică română.

WIRTH, J. (1989). L'Image médiévale. Naissance et développements $\left(V I^{e}-X V^{e}\right.$ siècles). Paris: Méridiens Klincksieck. 